Supporting information for

\title{
Monitoring mitophagy via FRET mechanism: Visualizing mitochondria, lysosomes, and autolysosomes in three different sets of fluorescence signals
}

\footnotetext{
Qingqing Lu, ${ }^{\mathrm{a}, \mathrm{c}}$ Wenpeng Li, ${ }^{\mathrm{a}}$ Kaiyuan Chen, ${ }^{\mathrm{a}}$ Minggang Tian ${ }^{\mathrm{b} *}$

${ }^{\text {a }}$ Engineering \&Technology Center of Electrochemistry, School of Chemistry and Chemical Engineering, Qilu University of Technology (Shandong Academy of Sciences), Jinan 250353, China.

b School of Chemistry and Chemical Engineering, University of Jinan, Jinan, Shandong 250022, People's Republic of China. E-mail: ifp_tianmg@ujn.edu.cn

c Shandong Key Laboratory of Biochemical Analysis, College of Chemistry and Molecular Engineering, Qingdao University of Science and Technology, Qingdao 266042, China
} 


\section{Contents}

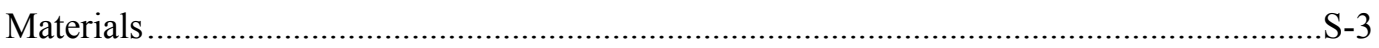

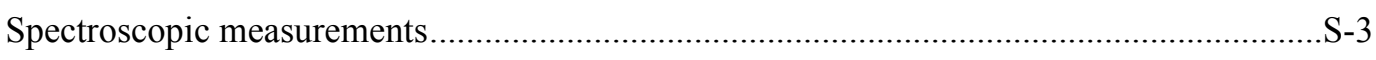

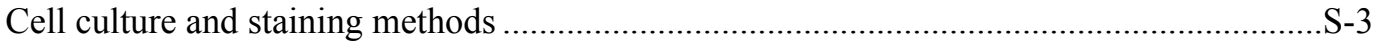

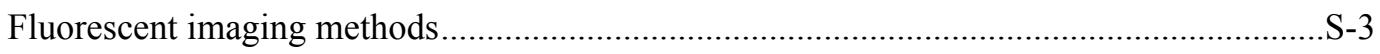

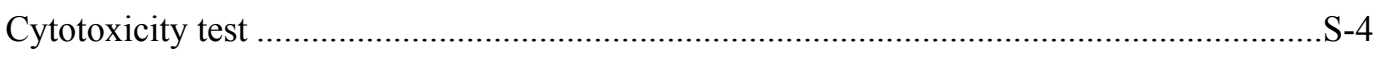

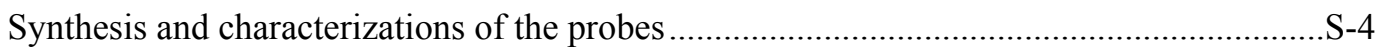

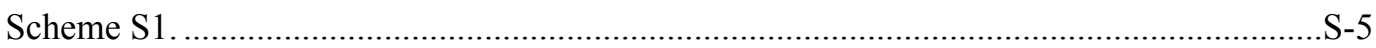

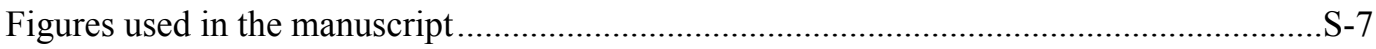

Figure S1. . . .

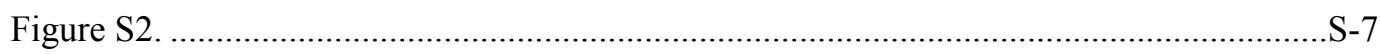

Figure S3, n-1

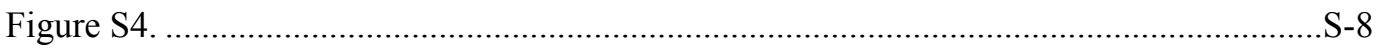

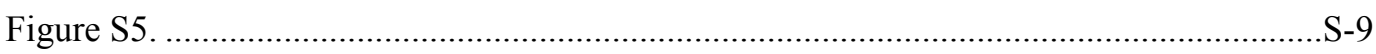

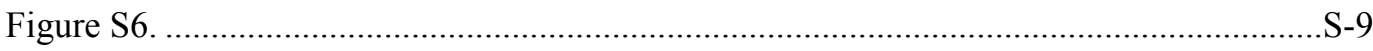

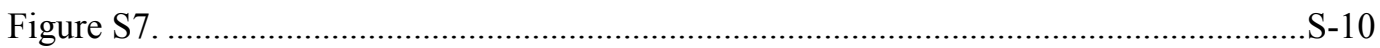

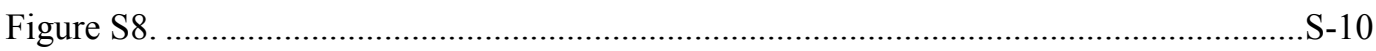

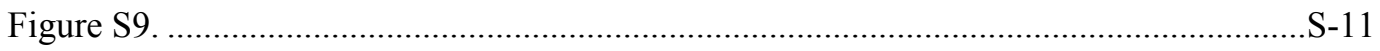

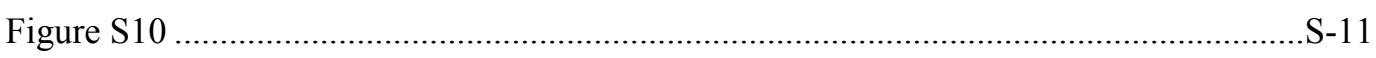

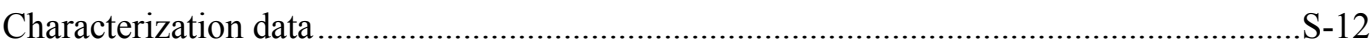

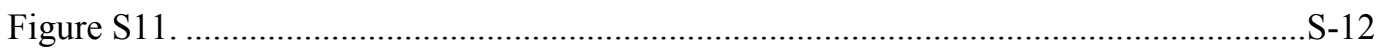

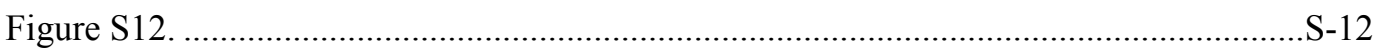

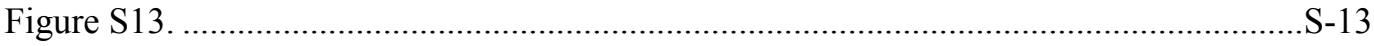

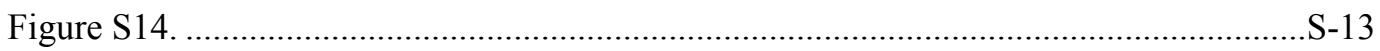

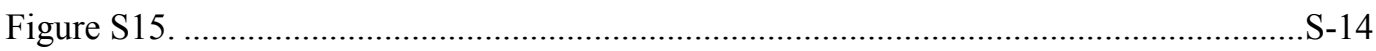

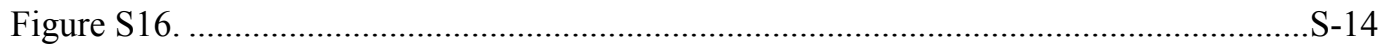

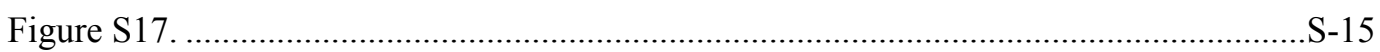




\section{Materials}

All chemicals used are of analytical grade, (4-bromophenyl)(methyl)sulfane, 4-vinylpyridine, resorcinol, 3-(piperazin-1-yl)phenol, and (4-(diethylamino)-2hydroxyphenyl)(2-hydroxyphenyl)methanone etc. were purchased from Sinopharm Chemical Reagent Co., Ltd (Shanghai, China). $\mathrm{K}_{2} \mathrm{CO}_{3}, \quad \mathrm{Pd}(\mathrm{AcO})_{2}$, Tri(o-tolyl)phosphine etc. was purchased from J\&K Chemical (Beijing, China). The solvents used in the spectral measurement are of chromatographic grade.

\section{Spectroscopic measurements}

The UV-visible-near-IR absorption spectra of dilute solutions were recorded on a U2910 spectrophotometer using a quartz cuvette having $1 \mathrm{~cm}$ path length. One-photon fluorescence spectra of dilute solutions were obtained on a HITACH F-2700 spectrofluorimeter equipped with a 450-W Xe lamp. PBS buffer solution: $10 \mathrm{mM}$, $\mathrm{NaCl}, \mathrm{NaHPO}_{4} \cdot 12 \mathrm{H}_{2} \mathrm{O}, \mathrm{NaH}_{2} \mathrm{PO}_{4} \cdot 2 \mathrm{H}_{2} \mathrm{O}, \mathrm{pH}=7.40$.

\section{Cell culture and staining methods}

HepG2 and A549 cells were bought from Procell Life Science\&Technology Co,.Ltd., and the cells were grown in H-DMEM (Dulbecco's Modified Eagle's Medium, High Glucose) supplemented with $10 \%$ FBS (Fetal Bovine Serum) in a $5 \% \mathrm{CO}_{2}$ incubator at $37{ }^{\circ} \mathrm{C}$. For living cells imaging experiment of the probes, the culture medium surrounding the cells were firstly removed, and the cells were washed with PBS twice. Then the cells were incubated in $1 \mathrm{~mL}$ of PBS. On the other hand, $1 \mathrm{mM}$ stock solutions of the probe in DMSO were prepared. After that, suitable amount of stock solutions were mixed evenly with $1 \mathrm{~mL}$ PBS ( $\mathrm{pH}$ 7.4) in a tube. The cells were incubated with the above mixed solutions at $37{ }^{\circ} \mathrm{C}$. After incubation, the cells were imaged immediately without further washing procedure.

\section{Fluorescent imaging methods}

Confocal fluorescence images were obtained with a Nikon A1R confocal laser scanning microscope. The fluorescent images of G-Mito and R-Lyso were acquired 
with the excitation of $405 \mathrm{~nm}$ and $561 \mathrm{~nm}$, respectively. The fluorescence in green and red channel was collected in the wavelength range of 500-550 $\mathrm{nm}$ and 570-620 $\mathrm{nm}$, respectively. For co-staining experiments, the commercialized probe (MTDR) was excited by $647 \mathrm{~nm}$, and the emission was collected in NIR channel (665-735 nm). The commercial probe (LYR) was excited by $561 \mathrm{~nm}$, and the emission was collected in red channel $(570-620 \mathrm{~nm})$. The commercial probe Hoechst33342 was excited by $405 \mathrm{~nm}$, and the emission was collected in blue channel (425-475 nm).

\section{Cytotoxicity test}

The cytotoxicity of the G-Mito and R-Lyso has been evaluated with HepG2 cells using the reagent MTT. A 96-well plate was used to perform the cell viability experiment. Suspension of HeLa cells with cell concentration of 10000 cells/mL was firstly prepared, and the suspension was added to the plate (200 $\mu \mathrm{L}$ per well). At the same time, culture medium without cells was also introduced into the wells $(200 \mu \mathrm{L}$ per well) as blank. The cells were incubated with $2 \mu \mathrm{M}$ of G-Mito, $4 \mu \mathrm{M}$ of R-Lyso, and their mixture for different time. Change the culture medium of all the wells, and after that $10 \mu \mathrm{L}$ of MTT $(5 \mathrm{mg} / \mathrm{mL})$ was added to each well. The well plate was incubated for $4 \mathrm{~h}$, and then the culture medium in each well was removed. $200 \mu \mathrm{L}$ of DMSO was added to dissolve the formazan, and finally the absorbance was measured with a microplate reader at $620 \mathrm{~nm}$. The cell survival rates were finally calculated following the equation below:

$$
\text { Survival Rate }(\%)=\left(A_{s}-A_{b}\right) /\left(A_{c}-A_{b}\right) \times 100 \%
$$

Where $A_{s}$ is the absorbance of the wells with cells treated with the probes, $A_{b}$ is the absorbance of wells pretreated with only culture medium, and $\mathrm{A}_{\mathrm{c}}$ is the absorbance of wells with cells treated with no reagents.

\section{Synthesis and characterizations of the probes}


(A)
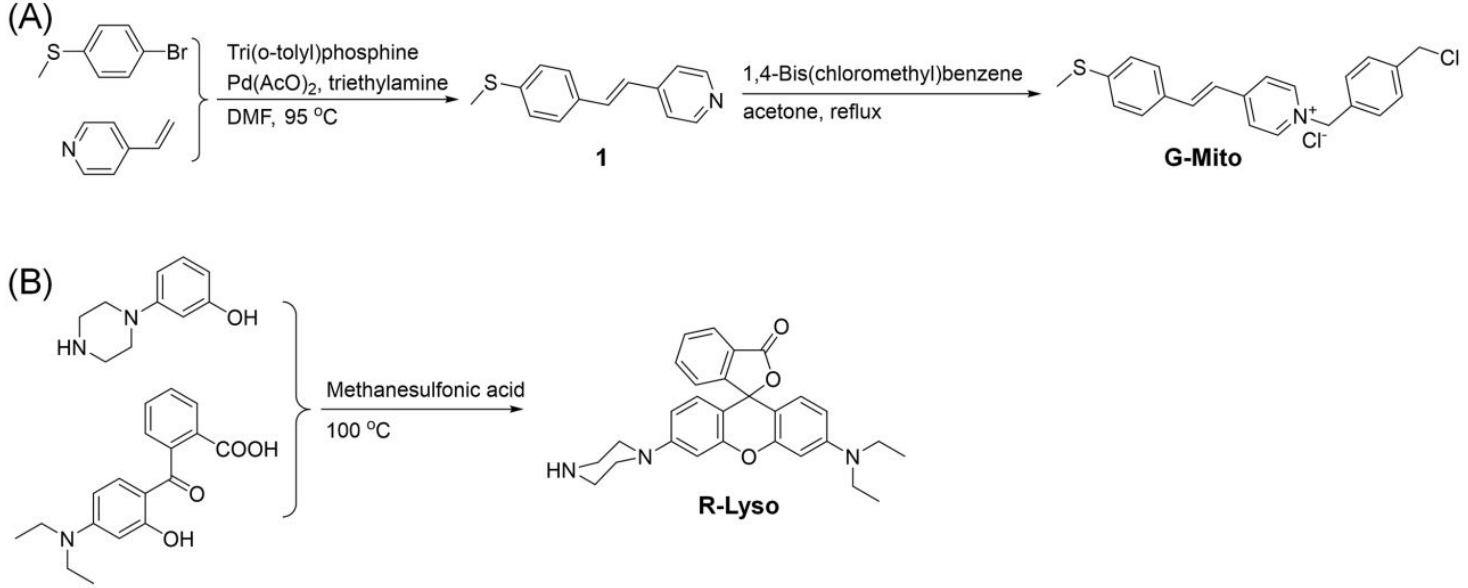

Scheme S1. The synthetic routine of G-Mito (A) and R-Lyso (B).

Synthesis of 4-(4-(methylthio)styryl)pyridine (1). (4-bromophenyl)(methyl)sulfane (0.20 g, $1 \mathrm{mmol})$, 4-vinylpyridine $(0.12 \mathrm{~mL}, 1.2 \mathrm{mmol}), \mathrm{Pd}(\mathrm{AcO})_{2}(0.022 \mathrm{~g}, 0.1$ mmol), and tri(o-tolyl)phosphine $(0.091 \mathrm{~g}, 0.3 \mathrm{mmol})$ were added into a flask. $20 \mathrm{~mL}$ of DMF was then added and the mixture was stirred vigorously. $5 \mathrm{~mL}$ of trimethylamine was added into the flask, and the reactants were heated to $90{ }^{\circ} \mathrm{C}$ under the protection of $\mathrm{N}_{2}$ atmosphere for $24 \mathrm{~h}$. The mixture were cooled down to room temperature and poured into $200 \mathrm{~mL}$ water. $150 \mathrm{~mL}$ dichloromethane was used to extract the product, which was then dried with anhydrous $\mathrm{MgSO}_{4}$, and distilled with rotary evaporator. The residue was purified by column chromatography with $\mathrm{CH}_{2} \mathrm{Cl}_{2} / \mathrm{MeOH}(\mathrm{v} / \mathrm{v}, 100: 1)$ as the eluent. The pure product was obtained as light yellow powder with the yield of 53\%. ${ }^{1} \mathrm{H}$ NMR (400 MHz, Chloroform- $d$ ) $\delta 8.67-$ $8.43(\mathrm{~m}, 2 \mathrm{H}), 7.50-7.41(\mathrm{~m}, 2 \mathrm{H}), 7.42-7.35(\mathrm{~m}, 2 \mathrm{H}), 7.32-7.20(\mathrm{~m}, 2 \mathrm{H}), 6.98(\mathrm{~d}$, $J=16.3 \mathrm{~Hz}, 1 \mathrm{H}), 2.52(\mathrm{~s}, 3 \mathrm{H})$.

Synthesis of 1-(4-(chloromethyl)benzyl)-4-(4-(methylthio)styryl)pyridin-1-ium chloride (G-Mito). The compound 1 (0.068 g, $0.030 \mathrm{mmol})$ and 1,4-bis (chloromethyl)benzene $(0.26 \mathrm{~g}, 0.15 \mathrm{mmol})$ were added into a flask. $10 \mathrm{~mL}$ of acetone were added to dissolve the reactants. The mixture was heated to reflux for $18 \mathrm{~h}$ to finish the reaction, which was cooled down to room temperature. Then large amount of solids were precipitated and filtered. The solids were recrystallized in acetone to 
afford the final product as yellow powder with yield of $87 \%$. ${ }^{1} \mathrm{H}$ NMR $(400 \mathrm{MHz}$, DMSO- $\left.d_{6}\right) \delta 9.06(\mathrm{~d}, J=6.6 \mathrm{~Hz}, 2 \mathrm{H}), 8.24(\mathrm{~d}, J=6.6 \mathrm{~Hz}, 2 \mathrm{H}), 8.01(\mathrm{~d}, J=16.3 \mathrm{~Hz}$, 1H), $7.76-7.65(\mathrm{~m}, 2 \mathrm{H}), 7.59-7.43(\mathrm{~m}, 4 \mathrm{H}), 7.41-7.32(\mathrm{~m}, 2 \mathrm{H}), 5.76(\mathrm{~s}, 2 \mathrm{H}), 4.78$ (s, 2H), 2.54 (s, 3H). ${ }^{13} \mathrm{C}$ NMR (101 MHz, DMSO) $\delta 153.94,144.78,142.53,141.38$, $139.15,135.20,131.95,130.06,129.60,129.40,129.14,126.19,124.46,122.60$, 46.18, 45.96, 14.63. HRMS (ESI): m/z, for $\mathrm{C}_{22} \mathrm{H}_{21} \mathrm{ClNS}^{+}$, Calc., 366.1087, found, 366.1081 .

Synthesis of 3'-(diethylamino)-6'-(piperazin-1-yl)-3H-spiro[isobenzofuran-1,9'xanthen]-3-one (R-Lyso). 2-(4-Diethylamino-2-hydroxybenzoyl) benzoic acid (0.94 g, $3.0 \mathrm{mmol})$ and 1-(3-hydroxyphenyl) piperazine $(0.54 \mathrm{~g}, 3.0 \mathrm{mmol})$ were added into a round-bottom flask. $8 \mathrm{~mL}$ of trifluoroacetic acid was added in and the mixture was stirred to mixed evenly. The system was heated to reflux for 8 hours, which was cooled down to temperature and poured into ice water. The precipitates were collected by filtration, which was further purified by column chromatography with $\mathrm{CH}_{2} \mathrm{Cl}_{2} / \mathrm{MeOH}(\mathrm{V}: \mathrm{V}=50: 1)$ as the eluent. The pure product presented as brown powder $(0.85 \mathrm{~g}$, yield of $62 \%) .{ }^{1} \mathrm{H}$ NMR $\left(400 \mathrm{MHz}\right.$, Methanol- $\left.d_{4}\right) \delta 8.21-7.97(\mathrm{~m}$, 1H), $7.70-7.63(\mathrm{~m}, 2 \mathrm{H}), 7.34-7.16(\mathrm{~m}, 3 \mathrm{H}), 7.19-7.04(\mathrm{~m}, 2 \mathrm{H}), 6.99$ (dd, $J=9.5$, $2.5 \mathrm{~Hz}, 1 \mathrm{H}), 6.90(\mathrm{~d}, J=2.5 \mathrm{~Hz}, 1 \mathrm{H}), 3.69-3.63(\mathrm{~m}, 8 \mathrm{H}), 1.30(\mathrm{t}, J=7.0 \mathrm{~Hz}, 7 \mathrm{H})$. ${ }^{13} \mathrm{C}$ NMR (101 MHz, DMSO) $\delta$ 169.29, 153.28, 152.92, 152.88, 152.58, 149.60, $135.84,130.37,129.09,128.75,127.04,124.92,124.51,111.90,109.07,108.86$, 105.34, 101.42, 97.34, 84.60, 48.19, 45.31, 44.26, 12.79. HRMS (ESI): m/z, for $\mathrm{C}_{28} \mathrm{H}_{30} \mathrm{~N}_{3} \mathrm{O}_{3}{ }^{+}$, Calc., 456.2282, found, 456.2285. 
Figures used in the manuscript

\begin{tabular}{|c|c|c|c|}
\hline \multirow{2}{*}{ Organelles } & \multicolumn{2}{|c|}{$\mathrm{Ex}=405 \mathrm{~nm}$} & \multirow{2}{*}{$\begin{array}{l}E x=561 \mathrm{~nm} \\
E m=590 \mathrm{~nm}\end{array}$} \\
\hline & $\mathrm{Em}=540 \mathrm{~nm}$ & $\mathrm{Em}=590 \mathrm{~nm}$ & \\
\hline Mitochondria & & & \\
\hline Lysosomes & & & \\
\hline Autolysosomes & & & \\
\hline
\end{tabular}

Figure S1. The proposed mode of G-Mito and R-Lyso to label mitochondria, lysosomes, and autolysosomes in three different sets of fluorescence signals.

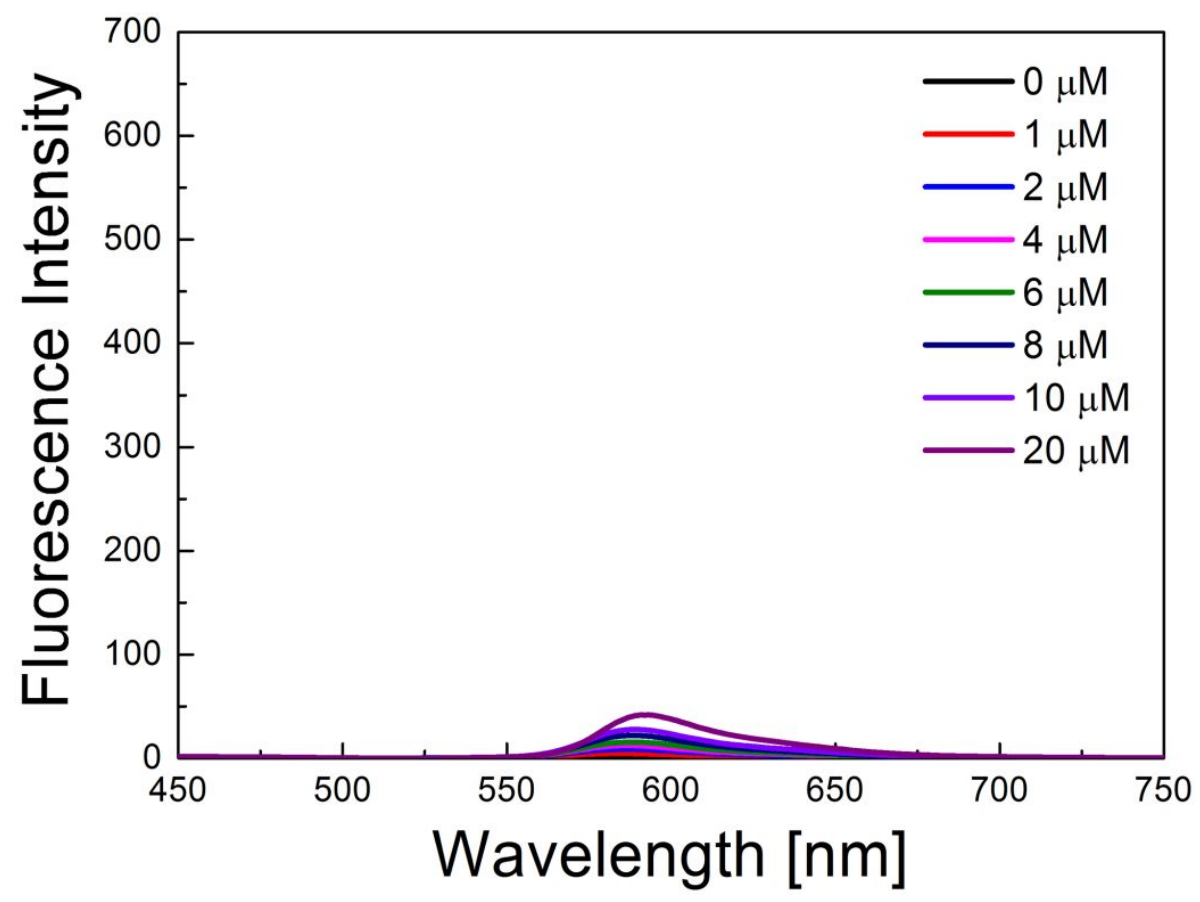

Figure S2. The fluorescence spectra of 1-20 $\mu \mathrm{M}$ R-Lyso with the excitation of 405 nm. 


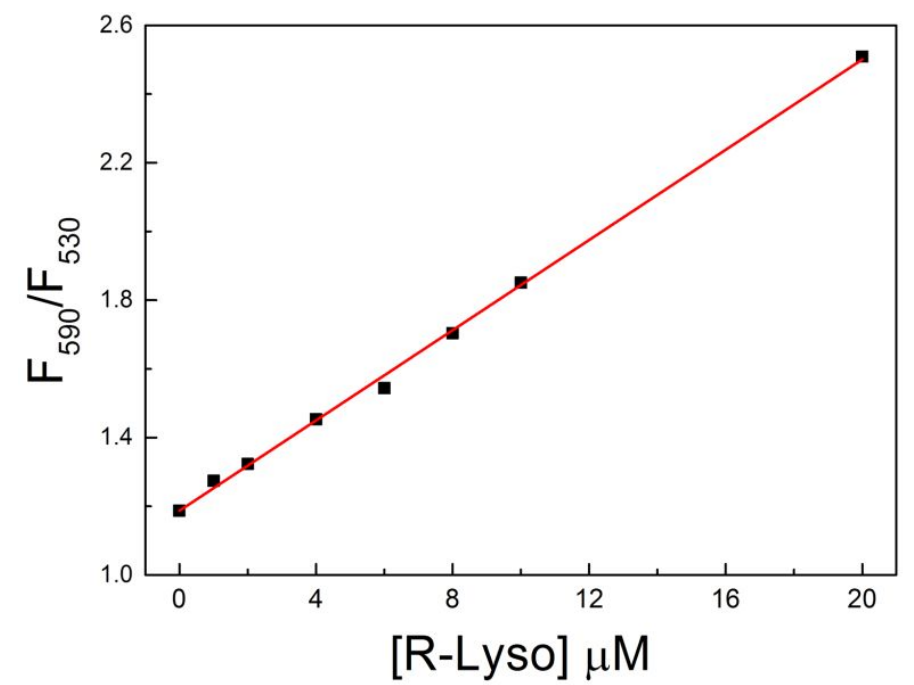

Figure S3. The emission intensity ratio $(590 \mathrm{~nm}$ to $530 \mathrm{~nm})$ of G-Mito $(2 \mu \mathrm{M})$ in the presence of 0-20 $\mu \mathrm{M}$ R-Lyso. Excitation wavelength: $405 \mathrm{~nm}$.

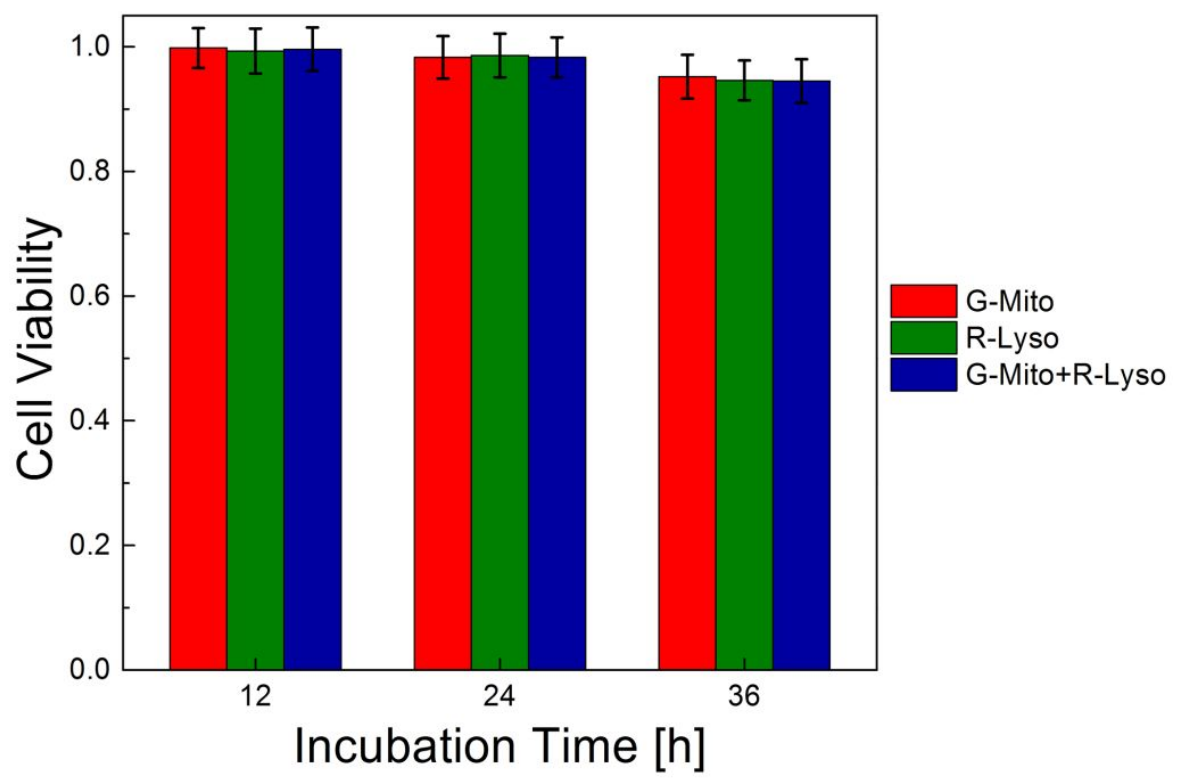

Figure S4. The cell viability of HepG2 cells incubated by $2 \mu \mathrm{M}$ of G-Mito, $4 \mu \mathrm{M}$ of R-Lyso, and their mixture for $12 \mathrm{~h}, 24 \mathrm{~h}$, and $36 \mathrm{~h}$. 

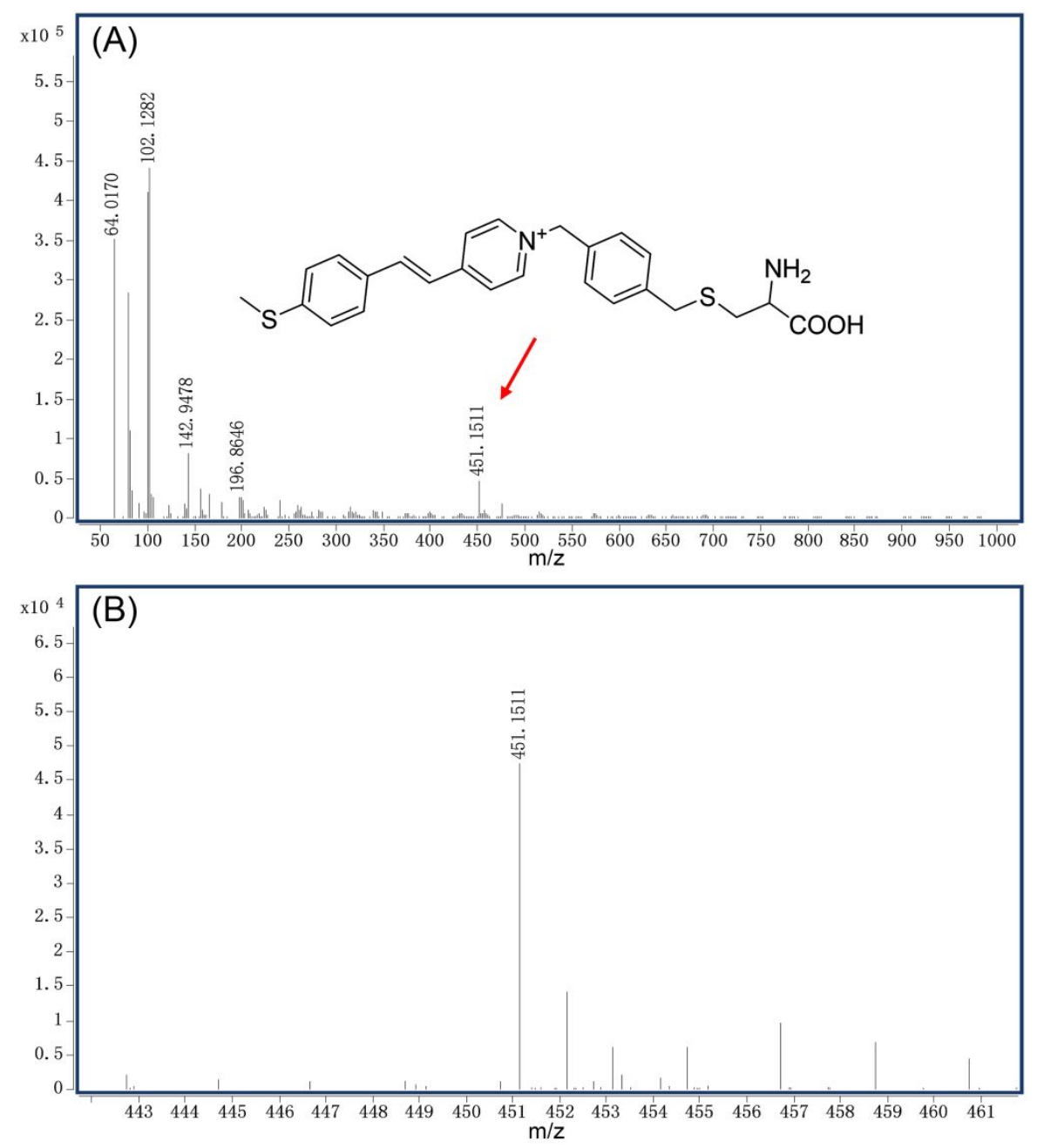

Figure S5. (A) The HRMS spectra of G-Mito $(50 \mu \mathrm{M})$ reacting with Cys $(1 \mathrm{mM})$ for 40 min in PBS buffer. (B) The local HRMS spectra of A.
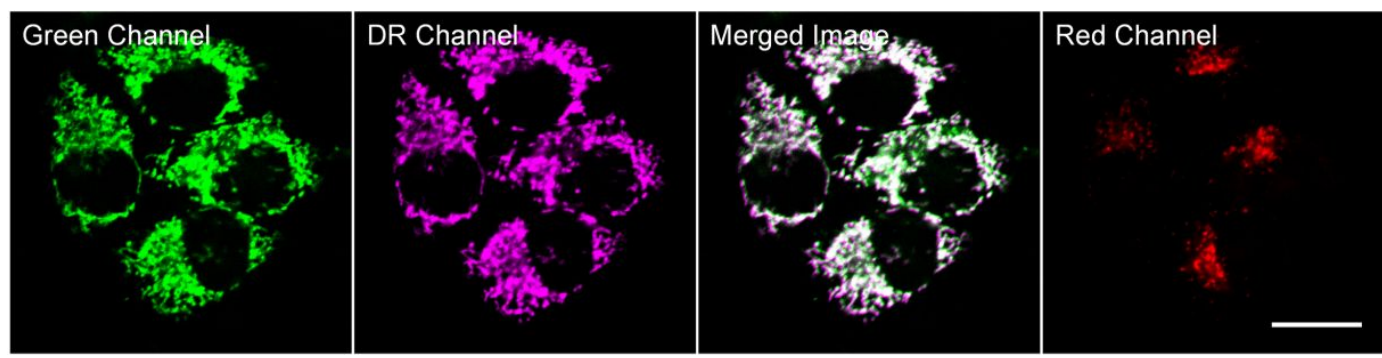

Figure S6. The fluorescence images of HepG2 cells incubated by $2 \mu \mathrm{M}$ G-Mito and 4 $\mu \mathrm{M}$ R-Lyso for $8 \mathrm{~h}$, and then stained by $200 \mathrm{nM}$ MTDR for $20 \mathrm{~min}$. Green Channel: $\lambda_{\mathrm{ex}}=405 \mathrm{~nm}, \lambda_{\mathrm{em}}=500-550 \mathrm{~nm}$; Red Channel: $\lambda_{\mathrm{ex}}=561 \mathrm{~nm}, \lambda_{\mathrm{em}}=570-620 \mathrm{~nm}$; Deep-red (DR) Channel: $\lambda_{\mathrm{ex}}=647 \mathrm{~nm}, \lambda_{\mathrm{em}}=665-735 \mathrm{~nm}$. Scale bar $=20 \mu \mathrm{m}$. 


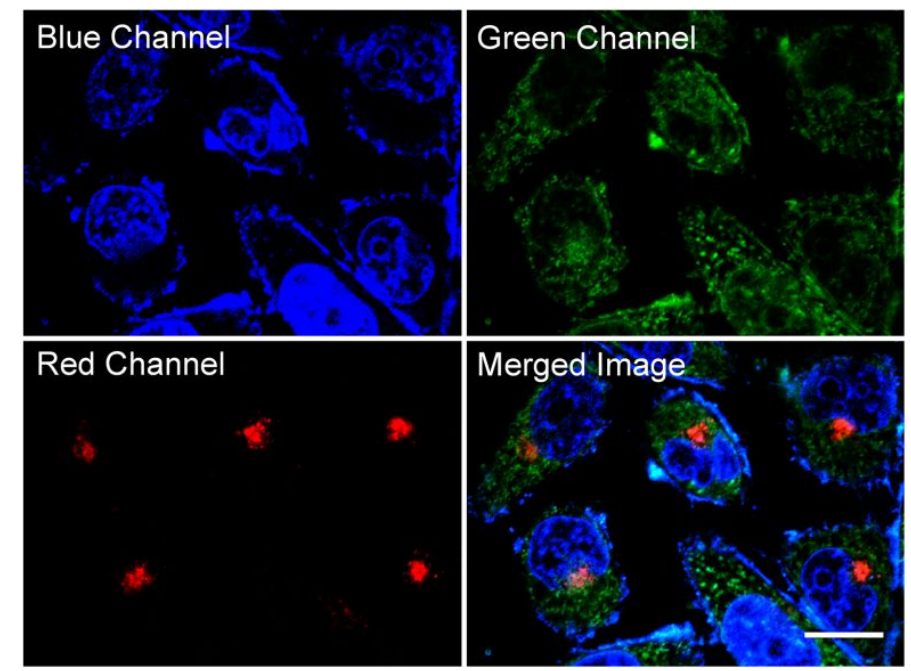

Figure S7. The fluorescence images of HepG2 cells co-stained by $2 \mu \mathrm{M}$ G-Mito, 4 $\mu \mathrm{M}$ R-Lyso, and $500 \mathrm{nM}$ Hoechst33342 for $40 \mathrm{~min}$, and then starved in D-Hanks buffer solutions for $4 \mathrm{~h}$. $\lambda_{\mathrm{ex}}=405 \mathrm{~nm}$; Blue Channel: $\lambda_{\mathrm{em}}=425-475 \mathrm{~nm}$; Green Channel: $\lambda_{\mathrm{em}}=500-550 \mathrm{~nm}$; Red Channel: $\lambda_{\mathrm{em}}=570-620 \mathrm{~nm}$. Scale bar $=20 \mu \mathrm{m}$.

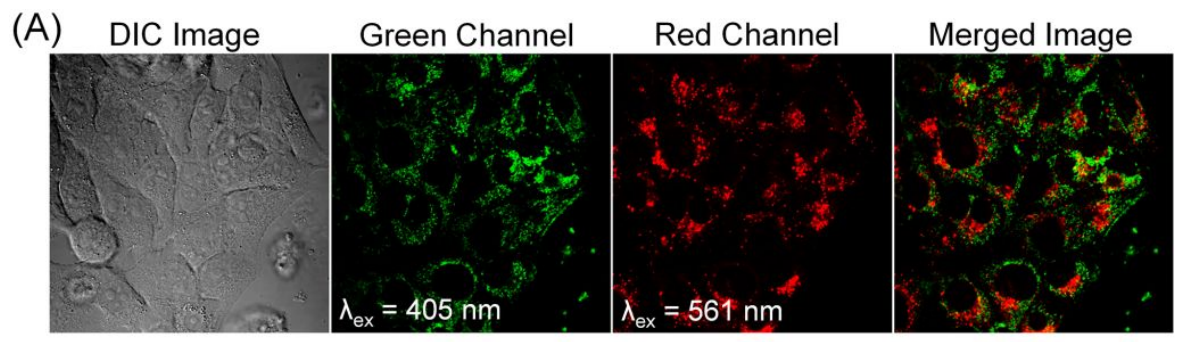

(B) Green Channel Red Channel Merged Image Ratiometric Image

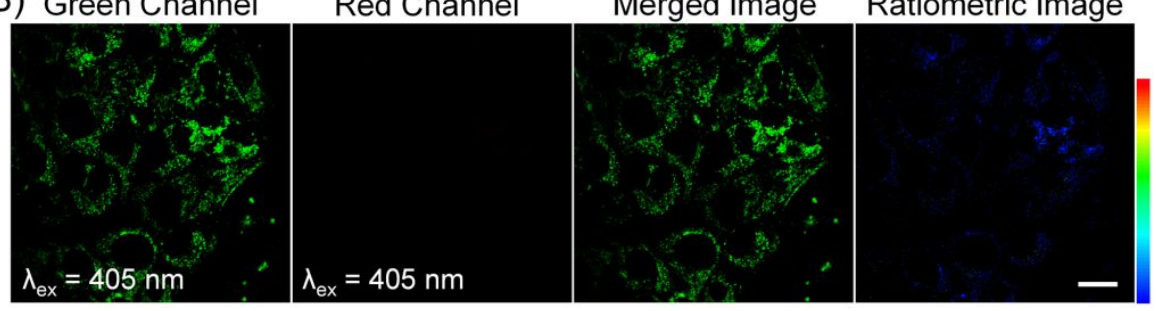

Figure S8. DIC, fluorescence, and ratiometric images of 4T1 cells co-incubated by 2 $\mu \mathrm{M}$ G-Mito and $4 \mu \mathrm{M}$ R-Lyso for $30 \mathrm{~min}$. In (A), Green Channel: $\lambda_{\mathrm{ex}}=405 \mathrm{~nm}, \lambda_{\mathrm{em}}=$ 500-550 nm; Red Channel: $\lambda_{\mathrm{ex}}=561 \mathrm{~nm}, \lambda_{\mathrm{em}}=570-620 \mathrm{~nm}$. In (B), $\lambda_{\mathrm{ex}}=405 \mathrm{~nm}$, Green Channel: $\lambda_{\mathrm{em}}=500-550 \mathrm{~nm}$; Red Channel: $\lambda_{\mathrm{em}}=570-620 \mathrm{~nm}$; ratiometric images were obtained by means of the intensity ratio of red to green channel. Scale bar $=20 \mu \mathrm{m}$. 

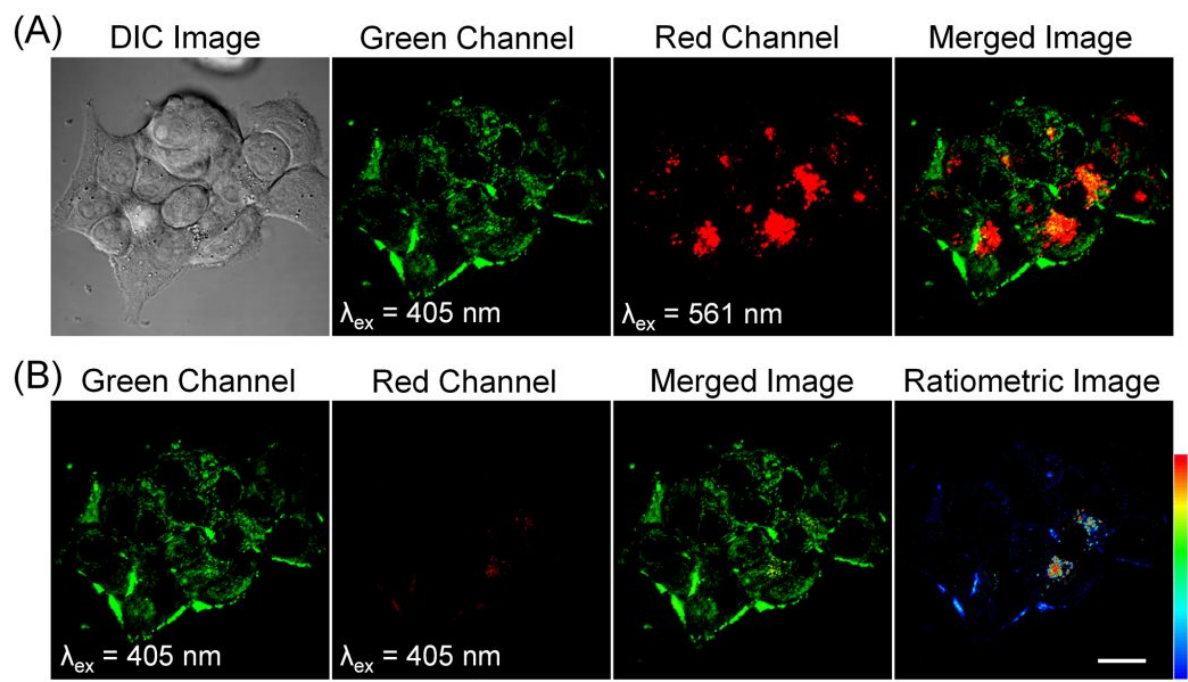

Figure S9. DIC, fluorescence, and ratiometric images of 4T1 cells co-incubated by 2 $\mu \mathrm{M}$ G-Mito and $4 \mu \mathrm{M}$ R-Lyso for $30 \mathrm{~min}$ and then starved in D-Hanks for $2 \mathrm{~h}$. In (A), Green Channel: $\lambda_{\mathrm{ex}}=405 \mathrm{~nm}, \lambda_{\mathrm{em}}=500-550 \mathrm{~nm}$; Red Channel: $\lambda_{\mathrm{ex}}=561 \mathrm{~nm}, \lambda_{\mathrm{em}}=$ 570-620 nm. In (B), $\lambda_{\mathrm{ex}}=405 \mathrm{~nm}$, Green Channel: $\lambda_{\mathrm{em}}=500-550 \mathrm{~nm}$; Red Channel: $\lambda_{\mathrm{em}}=570-620 \mathrm{~nm}$; ratiometric images were obtained by means of the intensity ratio of red to green channel. Scale bar $=20 \mu \mathrm{m}$.

(A)

\begin{tabular}{|c|c|c|c|c|c|}
\hline & & $\lambda_{\mathrm{ex}}=405 \mathrm{~nm}$ & & & $\lambda_{\mathrm{ex}}=561 \mathrm{~nm}$ \\
\hline DIC Image & Green Channel & Red Channel & Merged Image & Ratiometric Image & Red Channel \\
\hline $8 \mathrm{~h}$ & & * & $\sqrt{3}$ & 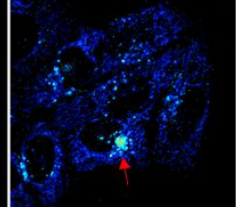 & $y^{2}$ \\
\hline $8 \mathrm{~h}-\mathrm{CQ}$ & & & & & \\
\hline
\end{tabular}

Figure S10. The DIC, fluorescence, and ratiometric images of HepG2 cells co-incubated by $2 \mu \mathrm{M}$ G-Mito and $4 \mu \mathrm{M}$ R-Lyso for $30 \mathrm{~min}$, and then incubated in culture medium for $8 \mathrm{~h}(\mathrm{~A})$, or incubated in culture medium containing $40 \mu \mathrm{M}$ CQ for 8h (B). Green Channel: $\lambda_{\mathrm{em}}=500-550 \mathrm{~nm}$; Red Channel: $\lambda_{\mathrm{em}}=570-620 \mathrm{~nm}$; ratiometric images were obtained by means of the intensity ratio of red to green channel. Scale bar $=20 \mu \mathrm{m}$. 


\section{Characterization data}

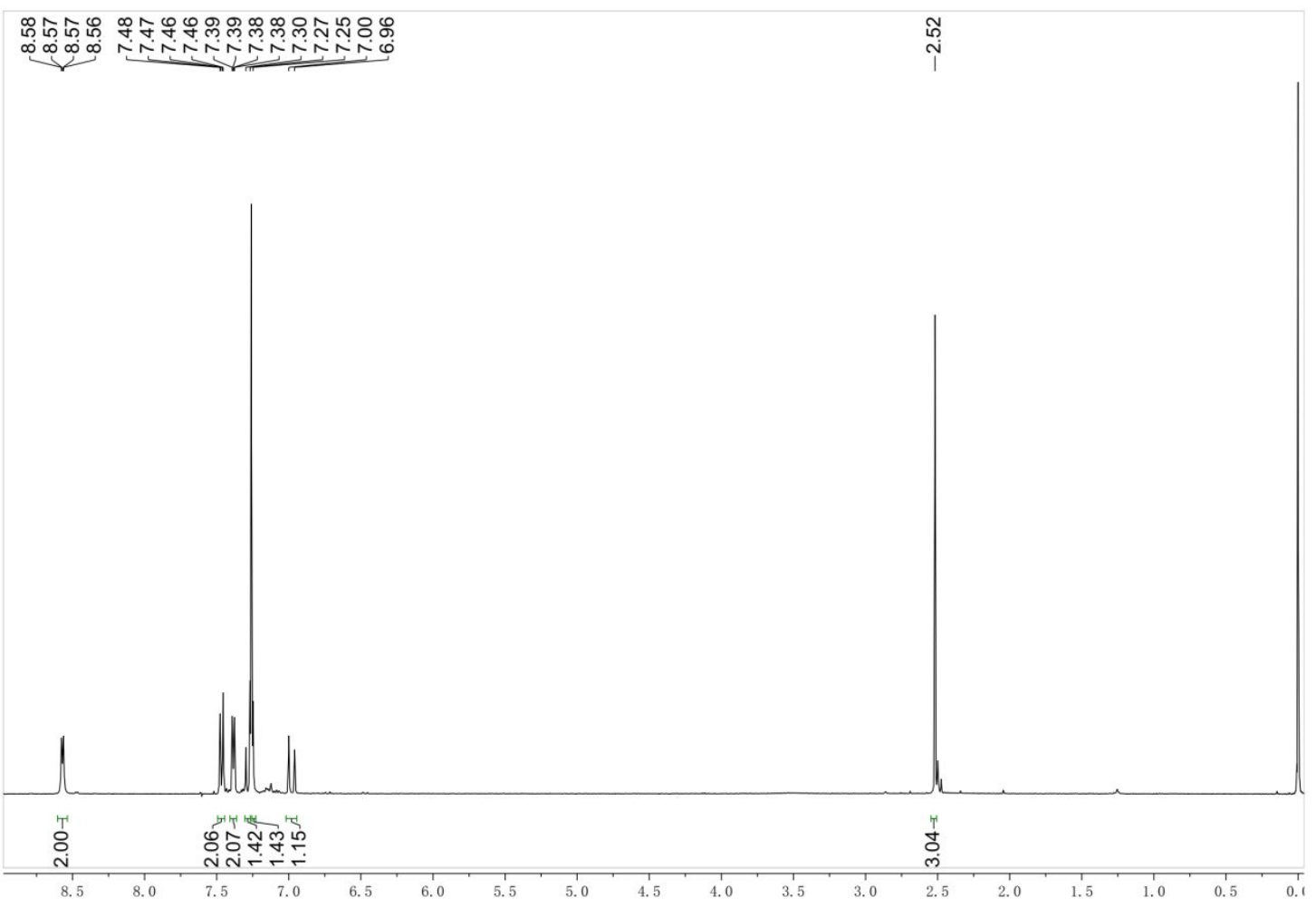

Figure S11. The ${ }^{1} \mathrm{H}$ NMR spectra of compound 1 in DMSO- $d_{6}$.

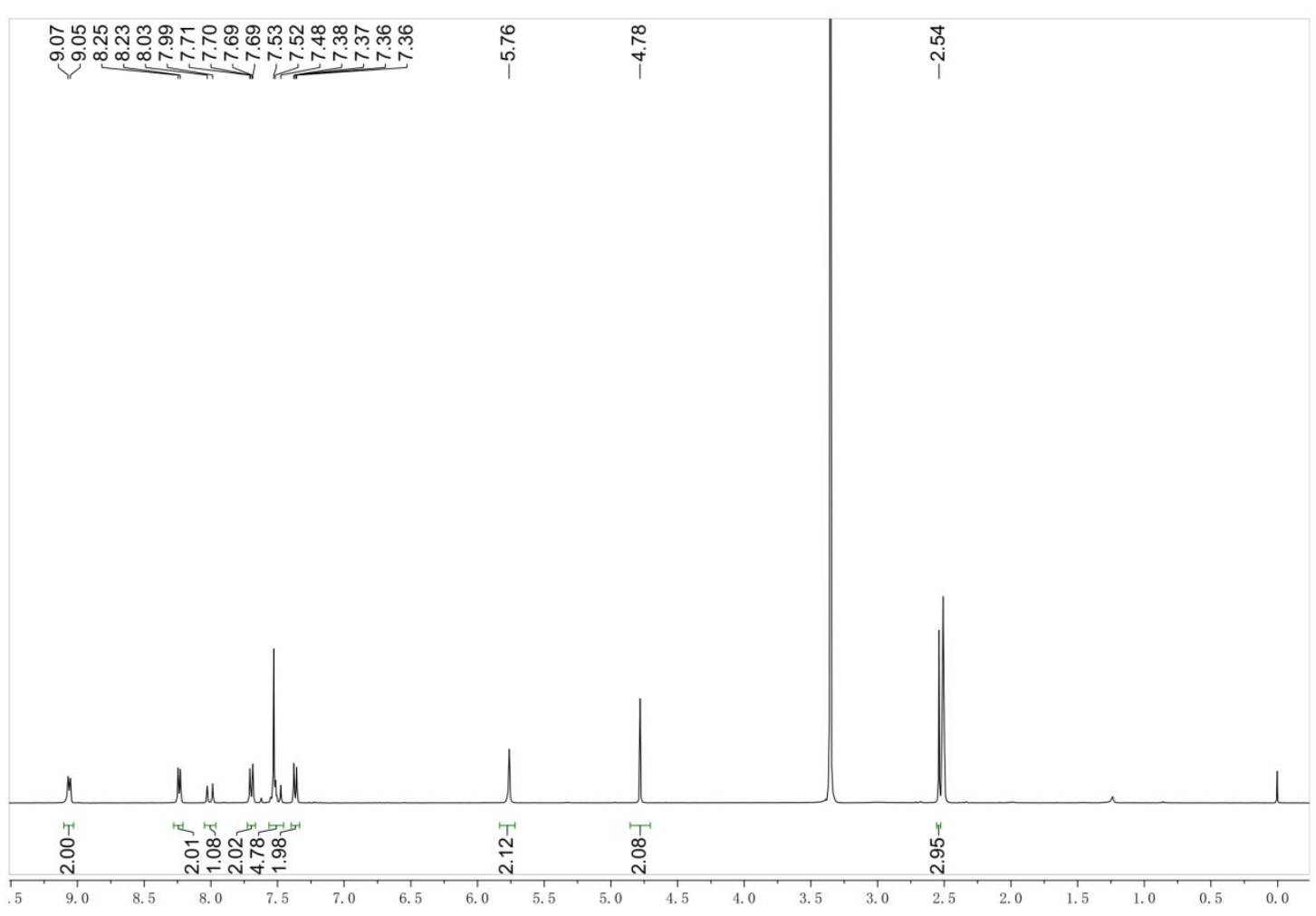

Figure S12. The ${ }^{1} \mathrm{H}$ NMR spectra of G-Mito in DMSO- $d_{6}$. 

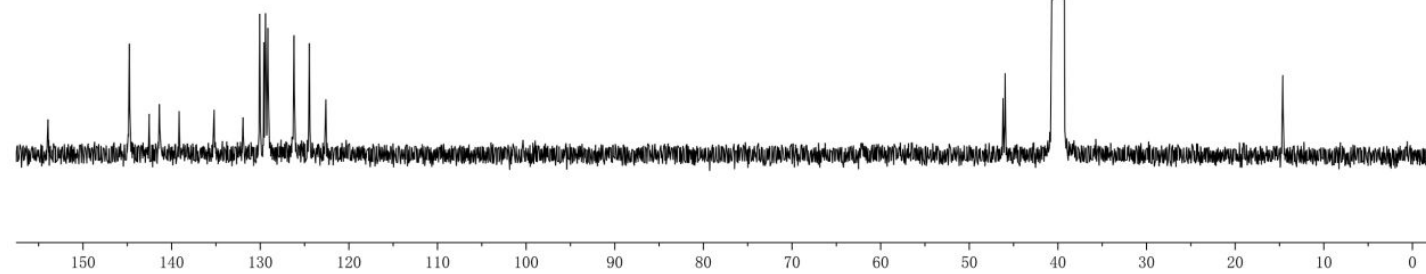

Figure S13. The ${ }^{13} \mathrm{C}$ NMR spectra of G-Mito in DMSO- $d_{6}$.

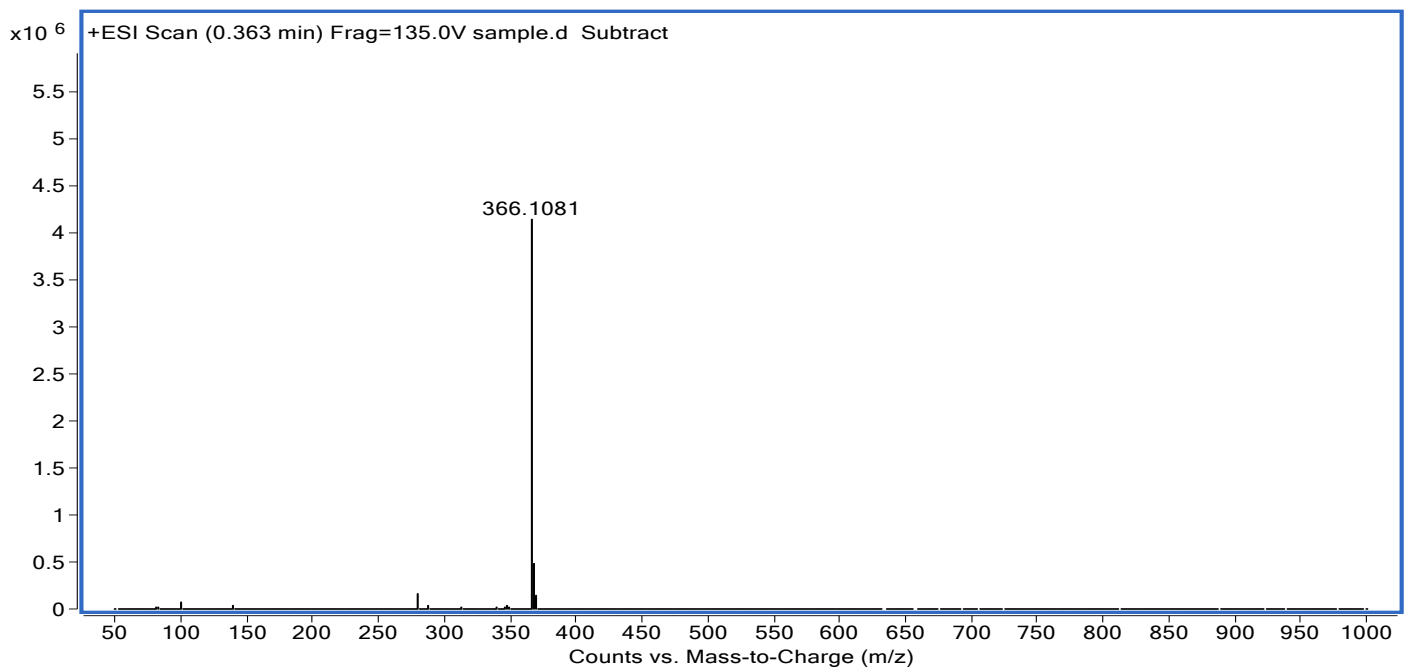

Figure S14. The HRMS spectra of G-Mito. 


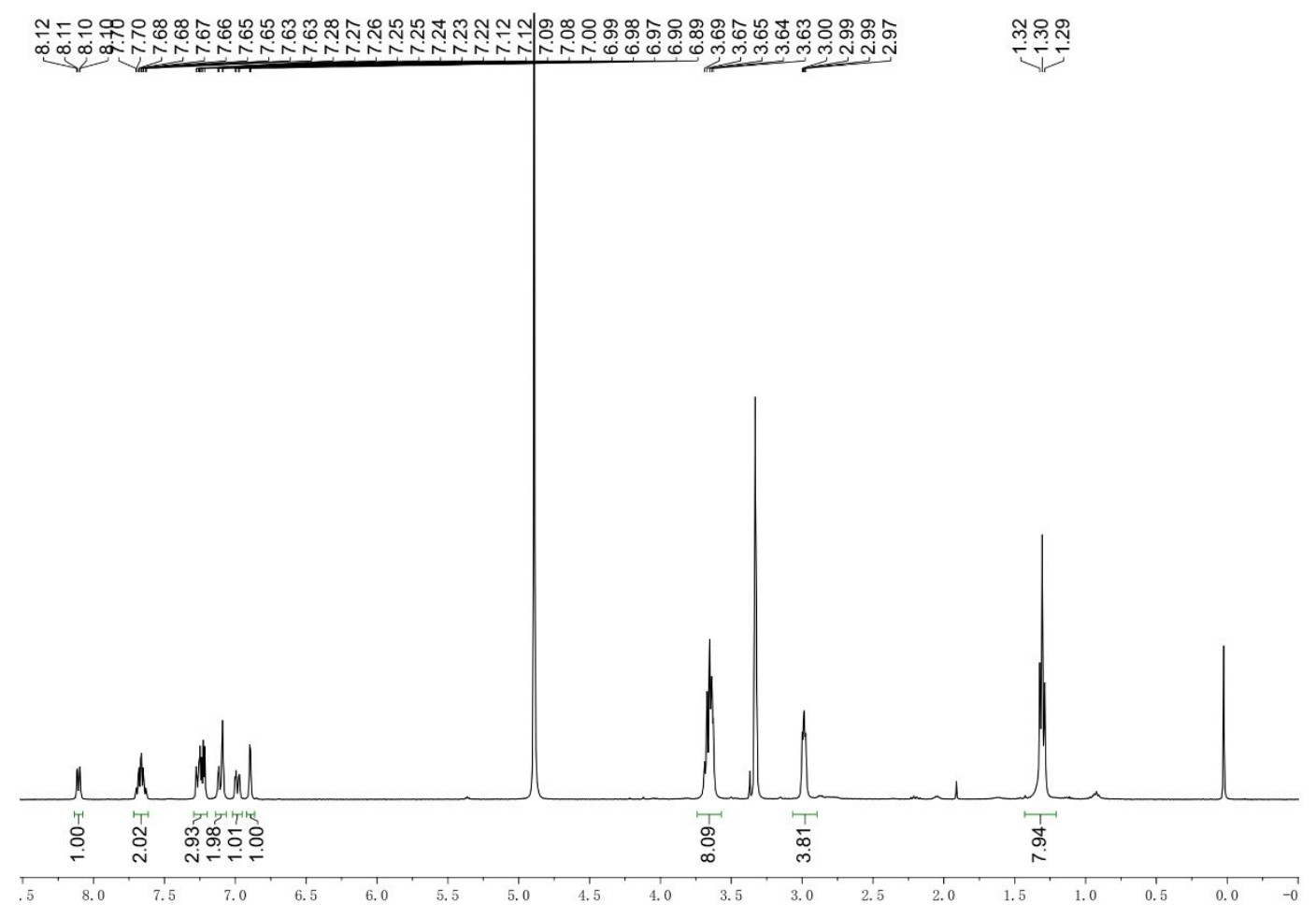

Figure S15. The ${ }^{1} \mathrm{H}$ NMR spectra of R-Lyso in DMSO- $d_{6}$.

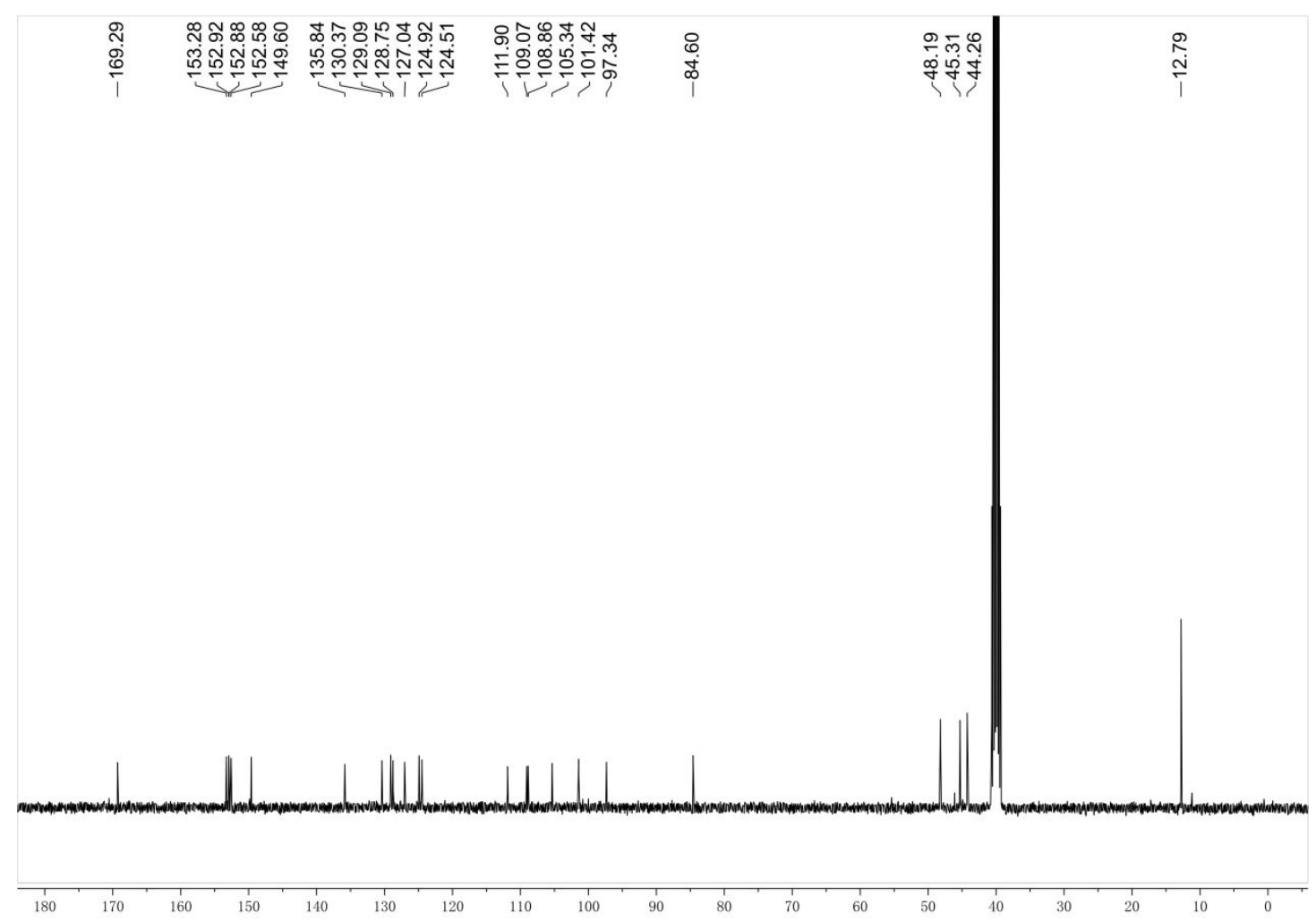

Figure S16. The ${ }^{13} \mathrm{C}$ NMR spectra of R-Lyso in DMSO- $d_{6}$. 


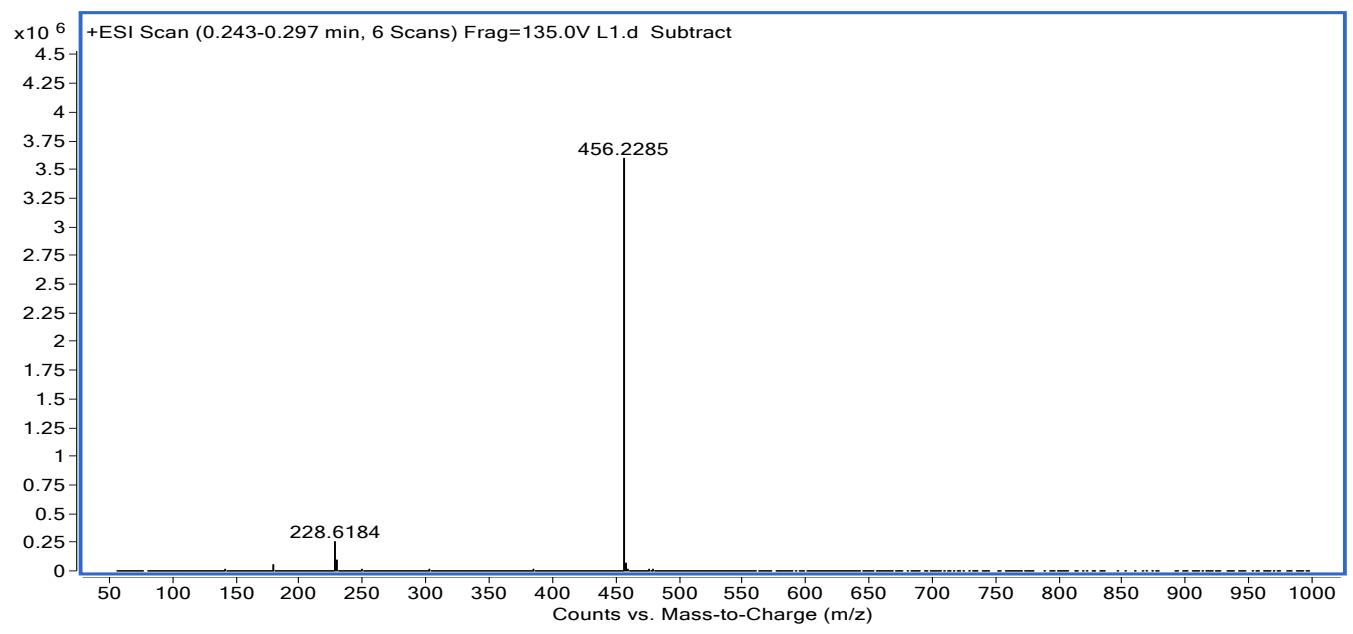

Figure S17. The HRMS spectra of R-Lyso. 